\title{
Correction to Riberio (2021)
}

The article The Quantification of Law: Counting, Predicting, and Valuating by Rafael Viana Ribeiro (Law, Technology and Humans, 3, no 1 (2021): 51-67. https://doi.org/10.5204/lthj.1603) was published on March 2, 2021. The author name has been changed at the request of the author. This corrected version of the article can be found at https://doi.org/10.5204/lthj.1966

Except where otherwise noted, content in this journal is licensed under a Creative Commons Attribution 4.0 International Licence. As an open access journal, articles are free to use with proper attribution. 